\title{
A model of oxygen and nitrogen biogeochemical response to hydrodynamic regimes in the Yarra River estuary
}

\author{
$\underline{\text { L.C. Bruce }}^{\mathrm{a}}$, P.L.M. Cook ${ }^{\mathrm{b}}$ and M.R. Hipsey ${ }^{\mathrm{a}}$ \\ a Aquatic Ecodynamics, School of Earth and Environment, The University of Western Australia, \\ Western Australia \\ ${ }^{b}$ Water Studies Centre, School of Chemistry, Monash University, \\ Victoria
}

Email: louise.bruce@uwa.edu.au

\begin{abstract}
Nitrogen biogeochemical response to alternative hydrodynamic regimes in estuaries that experience frequent anoxia has major implications for coastal water quality due to the significance of denitrification as a loss pathway for bioavailable nitrogen. The efficiency of nitrogen removal and storage in estuaries is dependent on a range of hydrodynamic and biogeochemical processes, in particular, the position of the salt wedge and effect of associated regions of anoxia. The purpose of this study was to demonstrate how rapidly shifting oxygen concentrations in the periodically anoxic Yarra River estuary, Australia, drive dynamic shifts in nitrogen cycles driving nitrogen assimilation efficiency of the estuary. Unravelling the complexity of the process response of nitrogen cycles in estuaries has been difficult to undertake empirically, so a numerical modelling approach is presented here to quantitatively predict variability in nitrogen assimilation, and demonstrate use as a tool to support optimal estuarine management.
\end{abstract}

A coupled 3D finite volume hydrodynamic-biogeochemical model of the estuary was developed to simulate flow, transport, mixing and biogeochemical reactions of oxygen and nitrogen, and used to quantify nitrogen cycling processes under alternative hydrodynamic regimes that occurred over a period of 12 months. The model was forced by boundary conditions that included meteorological data, inflow from two river sources and a tidally driven water level at the downstream boundary. Simulated concentrations of organic nitrogen, ammonium and nitrate were compared to measured data from field observations to evaluate model fit. Model output of both concentrations and process rates of mineralisation, nitrification, denitrification and sediment fluxes were analysed in relation to upstream nutrient loads under changing hydrodynamic regimes.

The model simulated observed patterns of both seasonal and spatial variation of inorganic and organic nitrogen in the estuary. A system-level validation comparing the deviation from mixing line for both ammonia and nitrate against oxygen concentrations also paralleled patterns in observed data. Simulated patterns of oxygen and nitrogen varied significantly over the simulated period both temporally and spatially. Tidal forcing balanced by changes in upstream flow volumes drove patterns of response in oxygen and nitrogen concentrations that varied across the model domain on both episodic and seasonal time-scales. Patterns of net nitrogen flux closely matched patterns of oxygen concentration. On a temporal scale, periods of low flow led to depleted oxygen concentrations, increase in sediment ammonium flux and reduction in rates of denitrification. During the dry summer season, episodic high flow events reversed this pattern over periods of 2-7 days. It was identified that low flows generally lead to an average positive net nitrogen flux across the estuary, whereas increased flows tend to switch the system towards a net negative nitrogen flux.

This application has demonstrated that utility of the model to unravelling the complex biogeochemical pathways that determine oxygen and nitrogen response to hydrodynamic regimes in a highly dynamic salt wedge estuary. Of particular interest to estuarine management is the pattern that emerged at the system-scale, whereby the volume of flow required to switch the net nitrogen budget of the estuary from positive (nitrogen source) to negative (nitrogen sink) was linked to the antecedent conditions that vary seasonally.

Keywords: Estuary eutrophication, nitrogen cycling, coupled hydrodynamic-biogeochemical model, anoxia, hypoxia 


\section{INTRODUCTION}

Coastal waters are generally nitrogen limited (Howarth and Marino 2006) whereby excess inorganic nitrogen entering marine environments can be a major factor regulating primary production (Herbert 1999), and may ultimately lead to harmful algal blooms (Hallegraef 1993). Estuaries form an important interface between the land and the sea, as estuarine processes can be a significant loss of catchment-sourced nitrogen, particularly through the process of denitrification (Nixon et al. 1996, Seitzinger 1988). In a study of estuaries of the North Atlantic Ocean, Nixon et al (1996) found estuaries are able to retain and remove $30-65 \%$ of terrestrially derived nitrogen that could otherwise enter nutrient limited coastal waters. A range of complex, non-linear hydrodynamic and biogeochemical processes mediate the efficiency of nitrogen storage and removal in estuaries. Of particular relevance to estuarine management is the elevated release of inorganic nitrogen from nutrient rich estuarine sediments observed under conditions of low dissolved oxygen in benthic waters (Cowan and Boynton 1996; Nowiki and Nixon 1985; Simon 1988). Understanding the processes that control nitrogen storage and removal in estuaries that experience variable patterns of anoxia therefore remains of fundamental importance in effective management of coastal catchments.

Acting as an interface between fresh river inflow and salty oceanic water, 'salt wedge' estuaries typically consist of regions defined by the position of the salt wedge. The location of the salt wedge within an estuary is highly dynamic, depending primarily upon the river discharge, river morphometry and tidal range

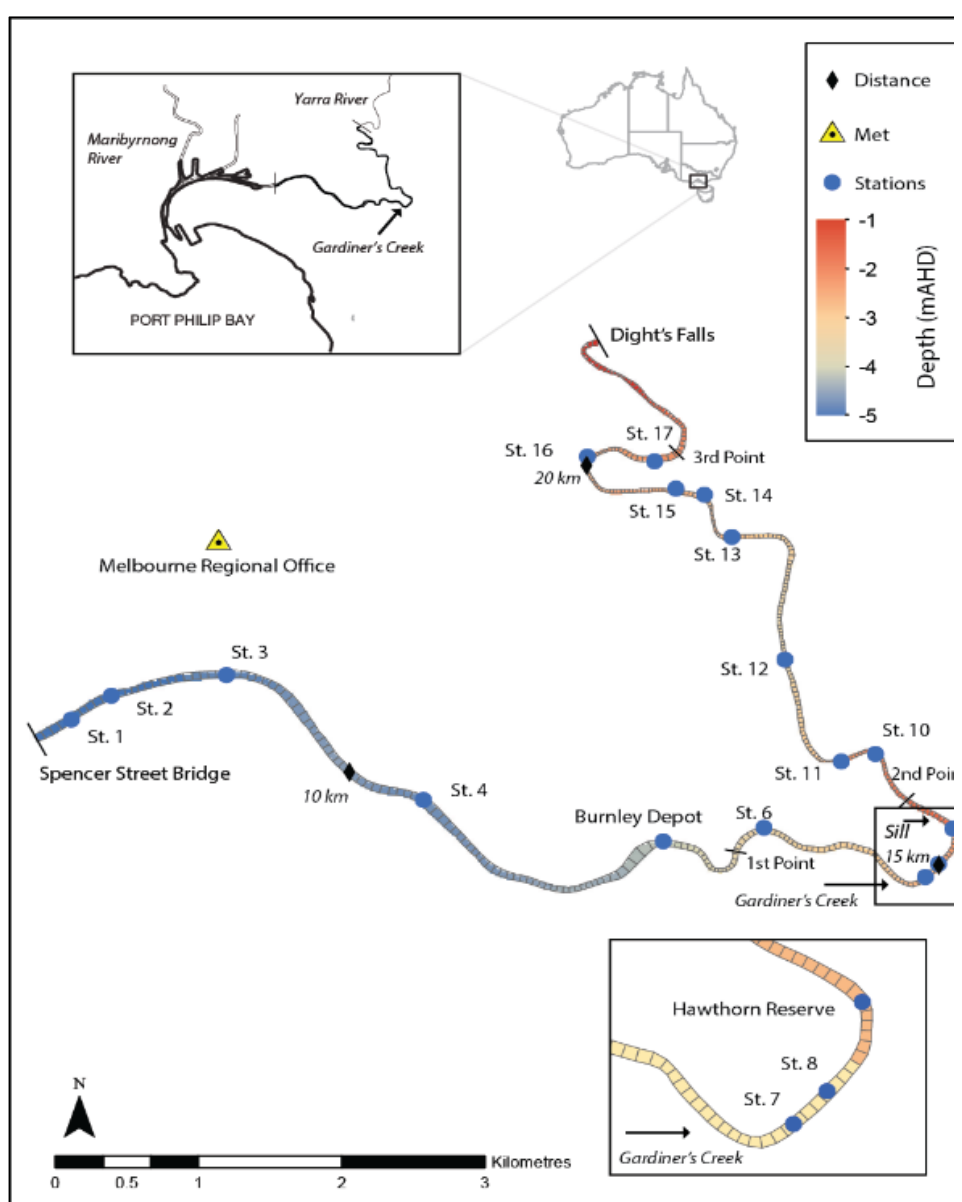

Figure 1. Study site, computational mesh, field stations and bottom depth elevation (AHD).

and under low river flow can potentially lead to regions of anoxia (Ishikawa et al. 2004; Lin et al. 2006). In the Yarra River estuary, Bruce et al. 2014 identified 4 distinct regions or zones separated by 3 geomorphic points of inflection (Figure 1). It was demonstrated that the oxygen depletion response differed in each of these zones as different physical processes dominated rates of mixing and stratification.

The nitrogen cycle of an estuary is intricately linked to oxygen concentrations whereby bottom water anoxia creates an environment favouring ammonia release and supressing sediment denitrification rates leading to a switch to water column denitrification (Brettar and Rheinheimer 1991; Hanning et al. 2007). Unravelling the complexity of the nitrogen cycle in response to changes in forcing boundary conditions is non-trivial, so a numerical modelling approach was adopted for this study in order to elucidate the nitrogen budget under varying hydrodynamic regimes. Here hydrodynamic regimes are defined both temporarily as flow events and spatially as geomophometric zones.

This study aims to:

1. Develop a coupled 3D hydrodynamic-biogeochemical model of the Yarra River estuary.

2. Determine the rates, dominant processes and fate of nitrogen (including sedimentation, mineralisation, nitrification, denitrification and flux across the sediment/water interface) in the estuary.

3. Assess how these rates respond to changes in hydrodynamic regimes within the estuary. 


\section{THE YARRA RIVER ESTUARY}

The Yarra River estuary is located in the highly urbanised city of Melbourne in southern Australia (Figure 1). The estuary exhibits a classic salt wedge circulation (Becket and Easton 1982) where the position of the salt wedge is highly dynamic and responds on two time scales of hours (tide and river flow) and months (river flow). Climate for Melbourne is temperate with warm summers (DecemberFebruary) and cooler winters (June-August), temperature ranges from $4-47^{\circ} \mathrm{C}$. Rain falls throughout the year with greatest fall from August to September. Past studies have found anoxia to be a widespread (up to $\sim 22 \mathrm{kms}$ upstream of the estuary mouth) and a common phenomenon during periods of low river flow (Roberts et al., 2012). Nitrate concentrations in the bottom waters were observed to drop sharply across the transition between the oxic and

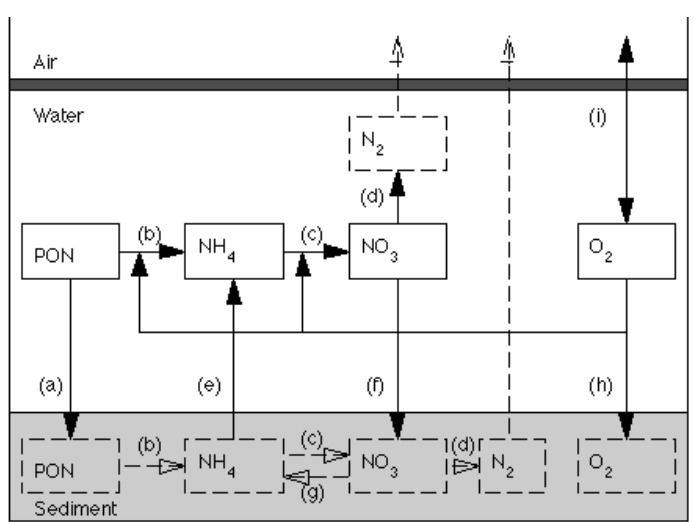

Figure 2. Schematic of AED2 model configuration applied to study the Yarra River estuary oxygen and nitrogen dynamics. anoxic layers of the salt wedge and laboratory experiments also confirmed water column denitrification (Roberts et al. 2012). Primary productivity in the estuary is inhibited by high levels of turbidity (Pettigrove 1990) and the sediments are generally aphotic.

\section{3D HYDRODYNAMIC-BIOGEOCHEMICAL MODEL}

\subsection{Hydrodynamic platform: TUFLOW-FV}

TUFLOW-FV is a finite volume 3-D hydrodynamic model (BMT WBM, 2013), used to simulate the water balance, mixing and transport processes in coastal environments. The model adopts a flexible mesh (in plan view), consisting of triangular and quadrilateral elements, and the vertical mesh discretization was set to use a $\mathrm{z}$-coordinate scheme for the lower water column and multiple surface Lagrangian layers. The numerical scheme solves the conservative integral form of the non-linear shallow water equations (NLSWE), the model also simulates the advection and transport of scalar constituents, including for salinity, temperature and the state variables from the coupled biogeochemical model.

Table 1. Parameter Summary.

\begin{tabular}{|c|c|c|}
\hline Symbol & Units & $\begin{array}{l}\text { Assigned } \\
\text { value }\end{array}$ \\
\hline$F_{\max }^{\mathrm{NH}_{4}}$ & $\mathrm{mmol} \mathrm{N} / \mathrm{m}^{2} / \mathrm{d}$ & $3.8^{\mathrm{a}}$ \\
\hline$K_{\text {sed }}^{\mathrm{NH}_{4}}$ & $\mathrm{mmol} \mathrm{O} / \mathrm{m}^{3}$ & $121.7^{\mathrm{a}}$ \\
\hline$\theta_{\text {sed }}^{\mathrm{NH}_{4}}$ & - & $1.08^{\mathrm{a}}$ \\
\hline$F_{\max }^{\mathrm{NO}_{3}}$ & $\mathrm{mmol} \mathrm{N} / \mathrm{m}^{2} / \mathrm{d}$ & $-0.92^{a}$ \\
\hline $\mathrm{K}_{\text {sed }}^{\mathrm{NO}_{3}}$ & $\mathrm{mmol} \mathrm{O} / \mathrm{m}^{3}$ & $37.3^{\mathrm{a}}$ \\
\hline$\theta_{\text {sed }}^{\mathrm{NH}_{4}}$ & - & $1.08^{\mathrm{a}}$ \\
\hline $\operatorname{Rmax}_{\text {nitrif }}$ & $/ \mathrm{d}$ & $0.2^{\mathrm{b}}$ \\
\hline$K_{\text {nitrif }}$ & $\mathrm{mmol} \mathrm{O} / \mathrm{m}^{3}$ & $78.1^{\mathrm{b}}$ \\
\hline$\theta_{\text {nitrif }}$ & - & $1.08^{\mathrm{b}}$ \\
\hline$R \max _{\text {denit }}$ & $/ \mathrm{d}$ & $0.26^{\mathrm{a}}$ \\
\hline$K_{\text {denit }}$ & $\mathrm{mmol} \mathrm{O} / \mathrm{m}^{3}$ & $21.8^{\mathrm{a}}$ \\
\hline$\theta_{\text {denit }}$ & - & $1.08^{\mathrm{a}}$ \\
\hline$\omega_{P O N}$ & $\mathrm{~m} / \mathrm{s}$ & $-1.0^{d}$ \\
\hline Rmax $_{\text {miner }}^{P O N}$ & $/ \mathrm{d}$ & $0.075^{\mathrm{c}}$ \\
\hline$K_{\text {miner }}^{P O N}$ & $\mathrm{mmol} \mathrm{O} / \mathrm{m}^{3}$ & $15.6^{\mathrm{c}}$ \\
\hline$\theta_{\text {miner }}^{P O N}$ & - & $1.08^{\mathrm{c}}$ \\
\hline \multicolumn{3}{|c|}{ Fitted to Roberts et al. (2012) } \\
\hline \multicolumn{3}{|c|}{ Robson and Hamilton (2004) } \\
\hline heng et al $(20$ & & \\
\hline
\end{tabular}

\subsection{Oxygen and Nitrogen Dynamics: AED2}

The Aquatic Ecosystem Dynamics (AED2) biogeochemical model was run with TUFLOW-FV to simulate nitrogen and oxygen within the estuary. For this study a simple configuration was adopted accounting for the processes of mineralisation and sedimentation of particulate organic nitrogen, nitrification, denitrification, oxygen exchange through the surface water and sediment water and flux of ammonium and nitrate across the sediment/water interface (Figure 2). For more detail refer to Hipsey et al. (2013). Parameters used in the biogeochemical model are included in Bruce et al. (2014) and Table 1. Phytoplankton were not included due to the highly turbid nature of the water column.

\subsection{Model Set Up}

The model domain starts with the downstream boundary condition at Spencer Street Bridge (chainage $=7.4 \mathrm{~km}$ ) and ends at the upstream boundary condition at Dight's Falls (chainage $=21.9 \mathrm{~km}$ ) (Figure 1). The model domain comprised a flexible mesh of 397 trapezoidal cells ranging from 213 to $7585 \mathrm{~m}^{2}$ in area. Refer to Bruce et al. (2014) and Jovanovic et al. (2015) for detailed description of model set up. 

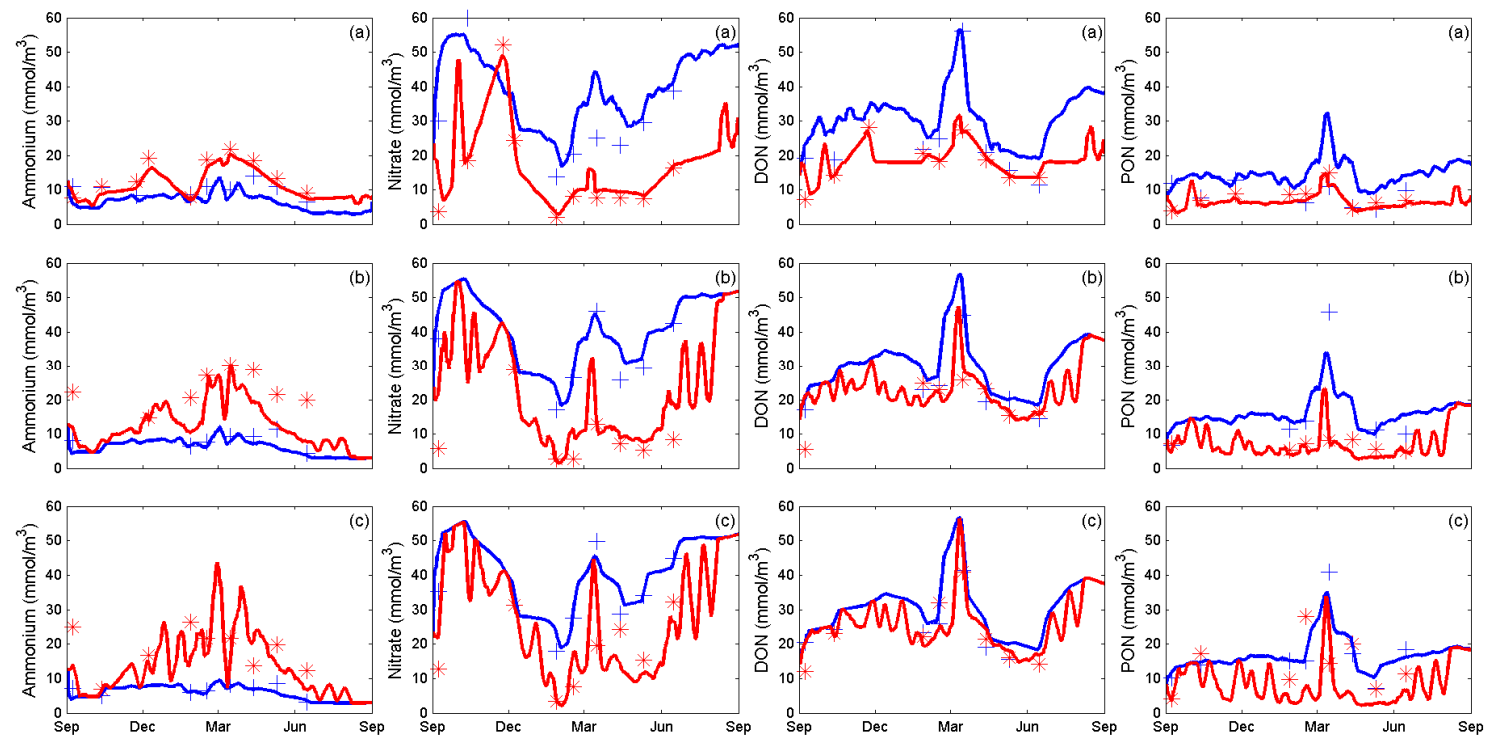

Figure 3. Time series data for surface (blue) and bottom (red) ammonium, nitrate, dissolved and particulate organic nitrogen for (a) Morell Bridge, (b) Scotch College, (c) Bridge Road. Crosses and asterisks represent observed data for surface and bottom concentrations respectively and solid lines simulated data.

\subsection{Boundary Conditions and Validation Data}

Hourly meteorological data was obtained from the Bureau of Meteorology Melbourne Regional Office (MRO) for air temperature, wind speed and direction, dew point temperature, precipitation and total cloud cover and was applied uniformly over the domain (Figure 1).

Gauged river discharge, temperature and salinity supplied by Melbourne Water at Dight's Falls and Gardiner's Creek (Figure 1) were included in the river boundary conditions with concentrations of biogeochemical state variables interpolated from monthly sampling data supplied by Monash University (Roberts et al. 2012). Similarly the downstream boundary condition at Spencer Street Bridge was forced using surface water elevations supplied by Melbourne water and temperature, salinity and concentrations of biogeochemical state variables interpolated from monthly sampling data supplied by Monash University (Roberts et al. 2012).

Depth profiles of biogeochemical data collected from nine along channel transects of surveys conducted between September 2009 and June 2009 were used to compare simulated and observed data (refer to Roberts et al., 2012). For each survey, depth profile data were collected at 5-6 of the 17 stations indicated in Figure 1. Time series comparisons of surface and bottom salinity, oxygen, ammonium, nitrate and dissolved and particulate organic nitrogen were made at three representative stations where greatest data were available: Morell Bridge (in the downstream end of the estuary); Scotch College (middle of the estuary) and Bridge Road (upstream end of the estuary) (Figure 1).
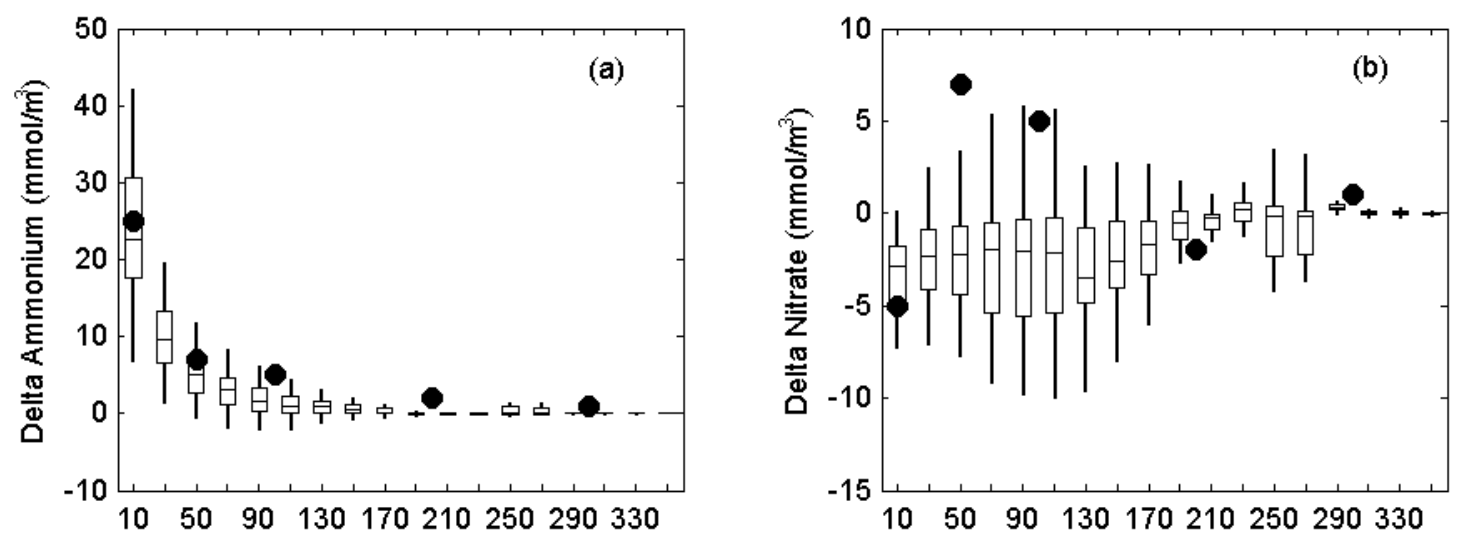

Figure 4. Deviation from conservative mixing for bottom concentrations of (a) ammonium and (b) nitrate as a function of oxygen concentration $\left(\mathrm{mmol} / \mathrm{m}^{3}\right)$. The box plots represent model output grouped every 20 $\mathrm{mmol} / \mathrm{m}^{3}$ of oxygen and the solid circles represent measured data (from Roberts et al. 2012). 

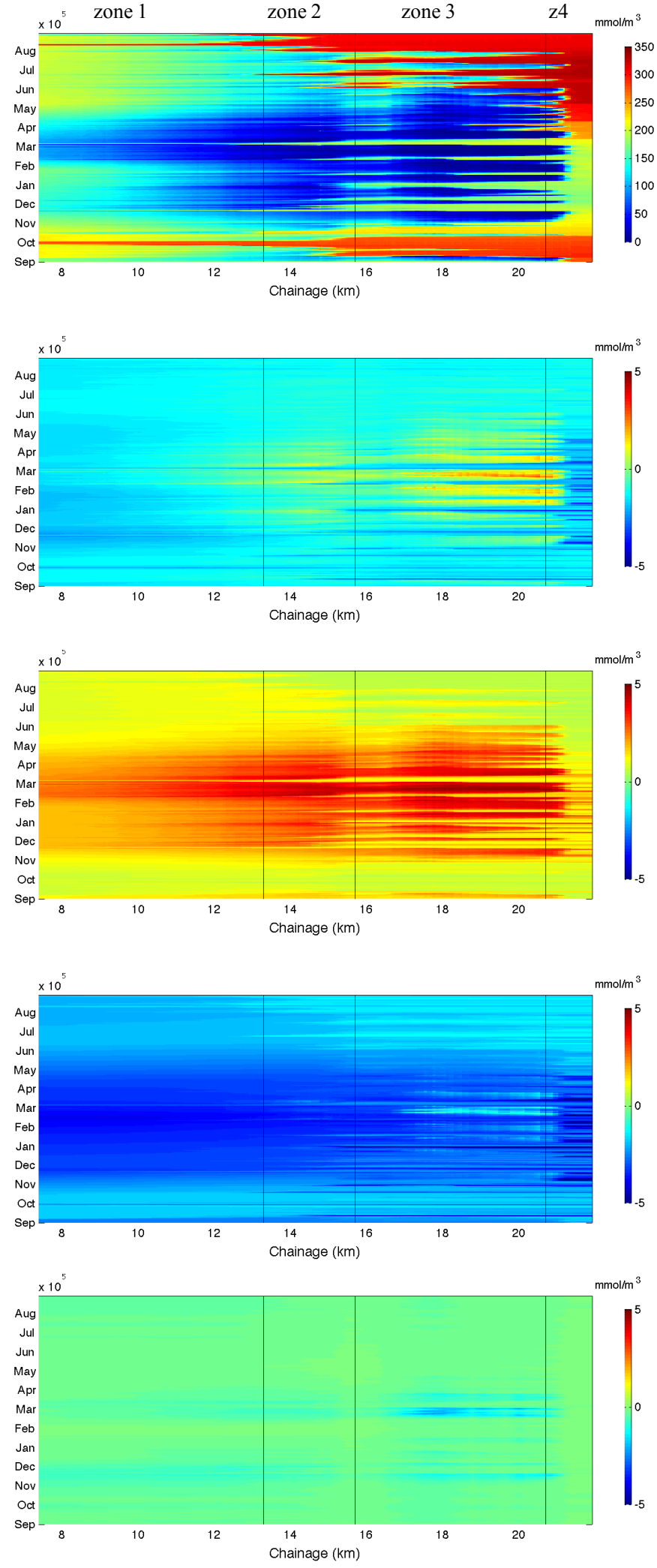

Figure 5. Predicted (a) bottom oxygen concentration $\left(\mathrm{mmol} / \mathrm{m}^{3}\right)$, (b) net nitrogen flux $\left(\mathrm{mmol} / \mathrm{m}^{2} /\right.$ day $),(\mathrm{c})$ ammonium sediment flux ( $\mathrm{mmol} / \mathrm{m}^{2} /$ day). (d) sediment denitrification $\left(\mathrm{mmol} / \mathrm{m}^{2} /\right.$ day), (e) water column denitrification $\left(\mathrm{mmol} / \mathrm{m}^{2} /\right.$ day)

\subsection{Validation and Assessment Approach}

The model predictions were compared against available profile and grab data for salinity, oxygen, $\mathrm{TN}, \mathrm{NO}_{3}$ and $\mathrm{NH}_{4}$. Five alternative measures of model fit parameters were used to quantify the error between observed data. The purpose was to both to enable comparison to similar modelling studies with various methods of performance evaluation, and also to apprise alternative model performance (Bennett et al., 2013). Measures of model fit included were: normalised mean absolute error (NMAE), root mean square error (RMSE), model efficiency (MEF), model skill score (MSS) and correlation coefficient (r). In addition a "system-scale" validation was performed comparing the deviation from mixing line for both ammonia and nitrate relative to oxygen concentrations against observed data.

\section{MODEL VALIDATION}

For a detailed description of model validation for water level, temperature, salinity and oxygen refer to Bruce et al. (2014) and Jovanovic et al. (2015).

Simulated time series of the surface and bottom concentrations of nitrogen state variables followed both the seasonal and episodic patterns observed in the field measurements (Figure 3). Similarly, spatial gradients from the river inflow to the estuary mouth were also captured by the model with a notable increase in bottom ammonium concentrations with distance from the downstream boundary at SSB. Measurements of model fit for nitrogen state variables were low compared to those for salinity and oxygen as cited in Bruce et al. (2014) (Table 3). The best model fit was for $\mathrm{NO}_{3}$ followed by $\mathrm{NH}_{4}, \mathrm{PON}$ and DON. The model fit for surface waters were higher than for bottom waters for the inorganic state variables and lower in the surface compared to bottom for the organic state variables. Reduced error in estimation of upstream boundary conditions would lead to more accurate predictions in surface waters for all four nitrogen state variables. The model was limited by using relatively sparse measurements relative to the high frequency of gauged flow rates.

Table 3. Model fit metrics for NH4, NO3, DON and PON. Normalised mean absolute error (NMAE), root mean square error (RMSE), model efficiency (MEF), model skill score (MSS) and correlation coefficient (r).

\begin{tabular}{|l|l|l|l|l|l|}
\hline Variable & NMAE & RMSE & MEF & MSS & $r$ \\
\hline NH4 & 0.31 & 0.4 & 0.13 & 0.76 & 0.59 \\
\hline NO3 & 0.27 & 0.29 & 0.29 & 0.80 & 0.76 \\
\hline DON & 0.41 & 0.31 & 0.42 & 0.85 & 0.10 \\
\hline PON & 0.58 & 0.29 & 0.29 & 0.80 & 0.26 \\
\hline
\end{tabular}


To demonstrate a system-level validation of the model results, the deviation from the conservative mixing line for both ammonium and nitrate were plotted against bottom concentrations of dissolved oxygen and compared to in-situ measurements made by Roberts et al (2012) (Figure 4). Although the nitrate results show a wider range of variability, the ammonium plot indicates a strong exponential relationship with oxygen as indicated also in the laboratory measurements.

\section{PROCESS SENSITIVITY TO HYDRODYNAMICS}

Similar to the seasonal patterns of simulated salt wedge intrusion and associated anoxia described by Bruce et al. (2014), the spatial extent of simulated nitrogen flux illustrates a strong response to both periods of relatively consistent high flow and episodic high flow events in the summer months (Figure 5). Seasonally, the net nitrogen flux is greatest in the summer months and lowest in the winter months with diversion from the general pattern occurring during episodic events in summer. The predominant nitrogen source and sink in the estuary were due to sediment ammonium flux and sediment denitrification, respectively (Figure 5c\&d). Although less significant for most of the year, nitrogen loss through water column de-nitrification was pronounced during the summer months.

Spatial patterns of nitrogen flux indicate that greatest ammonium flux and water column de-nitrification occurred in Zones 2 and 3 (indicated in Figure 1) similar to the "hot spots" of anoxia identified by Bruce et al. (2014). These regions of high flux are reduced at the interface or "point of inflection" between the zones.

To elucidate the effect of river flows and temperature on the net nitrogen flux of the Yarra River estuary, the net nitrogen flux was compared against river flow rate and bottom water temperature (Figure 6). The net nitrogen flux, or assimilation capacity, of the estuary (in $\mathrm{mmol} \mathrm{N} / \mathrm{m}^{2} / \mathrm{day}$ ), was calculated as the sum of denitrification in the water column, denitrification rate of the sediments and flux of ammonium from the sediments to the water column (all $\mathrm{mmol} \mathrm{N} / \mathrm{m}^{2} /$ day). The greatest nitrogen assimilation occurred during periods of average to high flow was generally negative with system-wide positive fluxes predicted to occur under high temperature and low flow conditions. A general pattern emerged of exponentially decreasing overall net flux with increased river flow. Interestingly, the rate of this relationship increased with increasing

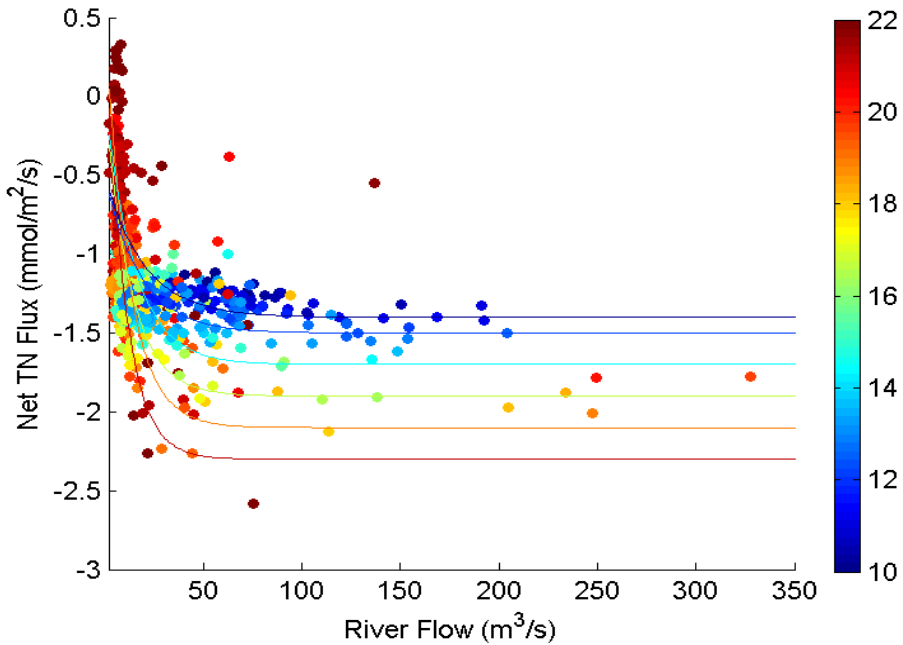

Figure 6. Net nitrogen flux (mmol/m2/day) against river flow $(\mathrm{m} 3 / \mathrm{s})$ where colour axis represents bottom water temperature $\left({ }^{\circ} \mathrm{C}\right)$ temperature as demonstrated by curve fitting to $2^{\circ} \mathrm{C}$ temperature intervals represented by solid lines (Figure 6).

\section{DISCUSSION AND CONCLUSIONS}

Based on current assumptions of model structure, configuration and parameterisation, analysis of simulated rates of nitrogen processes suggests that the Yarra River estuary generally exhibits a net nitrogen loss of assimilation for most of the year. Spatial patterns of nitrogen flux differed in the different estuarine zones identified in Bruce et al. (2014) (Figure 5). Greatest rates of sediment denitrification occurred in the deeper waters of zones $1 \& 2$ through most of the year and the shallowest region, zone 4 during periods of low flow (Figure 5d). Conversely a lower but significant nitrogen loss pathway via water column denitrification was greatest in zones $1 \& 3$ where mixing is reduced and stratification persists under conditions of low flow (Bruce et al. 2104). Extraction of process rate predictions from the model suggests that denitrification dominance switches from the sediments to water column in response to the corresponding multi-scale variability in hypoxia. The model simulated increased water column nitrification during periods of hypoxia in the bottom waters with concomitant reduced sediment denitrification rates. Rates of sediment denitrification (4-6 mmolN $/ \mathrm{m}^{2} / \mathrm{d}$ ) were consistent with those listed in Piña-Ochoa and ÁlvarezCobelas (2006) for estuaries on an annual average $\left(0.05-3.0 \mathrm{mmolN} / \mathrm{m}^{2} / \mathrm{d}\right)$ and for the warmest water temperature $\left(0.19-14.3 \mathrm{mmolN} / \mathrm{m}^{2} / \mathrm{d}\right)$. Water column rates of denitrification are rarely studied, but the rates simulated by the model $\left(0-2 \mathrm{mmolN} / \mathrm{m}^{2} / \mathrm{d}\right)$ are generally in line with estimates by Sundbäck and Miles (2002) 
Bruce et al., Biogeochemical response to hydrodynamic regimes in the Yarra River estuary

of $0.79-1.30 \mathrm{mmolN} / \mathrm{m}^{2} / \mathrm{d}$ for coastal ecosystems in Sweden but much lower than the range (60-81 $\mathrm{mmolN} / \mathrm{m}^{2} / \mathrm{d}$ ) measured by Laursen and Seitzinger (2002) in river systems.

Over the full study domain, the simulated average total rate of denitrification did not vary significantly from conditions of low flow $\left(6 \mathrm{mmolN} / \mathrm{m}^{2} / \mathrm{d}\right)$ to high flow $\left(7 \mathrm{mmolN} / \mathrm{m}^{2} / \mathrm{d}\right)$. This was in part due to the reduction in sediment denitrification made up for in the switch to water column denitrification under anoxic conditions and a significant base denitrification independent of oxygen concentrations in the water column.

This model study has therefore been able to provide insights into the complex biogeochemical processes that determine oxygen and nitrogen response to hydrodynamic regimes in a highly dynamic salt wedge estuary. Of particular interest to estuarine management is the suggestion that potentially even a small volume of flow can switch the net nitrogen budget of the estuary from positive (nitrogen source) to negative (nitrogen sink) at the height of summer. This may be a useful indicator for setting of environmental flows, bearing in mind that preventing extreme low flows through environmental water provision may reduce the overall load of nutrients to the downstream coastal embayment.

\section{ACKNOWLEDGMENTS}

This work was supported by Melbourne Water, Victorian Environment Protection Authority and the Australian Research Council (grant LP0991254). Data used for model parameterisation and validation was provided by Keryn Roberts from field and laboratory studies conducted by Monash University. Software development and technical support was provided by Ian Teakle from BMT WBM and Casper Boon and Brendan Busch from the Aquatic EcoDynamics group at The University of Western Australia.

\section{REFERENCES}

Bennett, N.D., B.F.W. Croke, G. Guariso, J.H.A. Guillaume, S.H. Hamilton, A.J. Jakeman, S. Marsili-Libelli, L.T.H. Newham, J.P. Norton, C. Perrin, S. Pierce, B. Robson, R. Seppelt, A. Voinov, B.D. Fath and V. Andreassian (2013). Characterising performance of environmental models, Environmental Modelling and Software, 40, 1-20.

Brettar, I., and G. Rheinheimer (1991). Denitrification in the Central Baltic: evidence for H,S-oxidation as motor of denitrification at the oxic-anoxic interface. Marine Ecological Progress Series, 77, 157-169.

Bruce, L.C., P.L.M. Cook, and M.R. Hipsey (2014). Hydrodynamic controls on oxygen dynamics in a riverine salt wedge estuary, the Yarra River estuary, Australia. Hydrology and Earth Systems Science, 18, 1397-1411.

BMT WBM (2013). TUFLOW FV Science Manual, available at: http://www.tuflow.com/ProductDownload.aspx?tuffv, 2013.

Hannig, M., G. Lavik, M.M.M. Kuypers, D. Woebken, W. Martens-Habbena, and K. Jürgens (2007). Shift from denitrification to anammox after inflow events in the central Baltic Sea. Limnology \& Oceanography, 54, 1336-1345.

Hipsey, M.R., L.C. Bruce, and D.H. Hamilton (2013). Aquatic Ecodynamics (AED) Model Library Science Manual, available at: http://aed.see.uwa.edu.au/research/models/AED/Download/AED_ScienceManual_v4_draft.pdf

Ishikawa, T., I. Suzuki, and X. Qian (2004). Hydraulic study of the onset of hypoxia in the Tone River Estuary. Journal of Environmental Engineering, 130, 551:561.

Jovanovic, D., M.P. Barnes, I.A.L. Teakle, L.C. Bruce, and D.T. McCarthy (2015). 3D Hydrodynamics and vertical mixing in a stratified estuary. MODSIM2015 - 21st International Congress on Modelling and Simulation. Modelling and Simulation Society of Australia and New Zealand, November 2014, Gold Coast, Australia.

Lin, J., L. Xie, L.J. Pietrafesa, J. Shen, M.A. Mallin, and M.J. Durako (2006). Dissolved oxygen stratification in two microtidal partially-mixed estuaries. Estuarine and Coastal Shelf Science, 70, 423-437.

Nixon, S.W., J.W. Ammerman, L.P. Atkinson, V.M. Berounsky, G. Billen, W.C. Biocourt, W.R. Boynton, T.M. Church, D.M. Di Toro, R. Elmgren, J.H. Garber, A.E. Giblin, R.A. Jahnke, N.J.P Owens, M.E.Q. Pilson, and S.P. Seitzinger (1996). The fate of nitrogen and phosphorus at the land-sea margin of the North Atlantic Ocean. Biogeochemistry 35, $141-180$

Roberts, K.L., V.M. Eate, B.D. Eyre, D.P. Holland, and P.L.M Cook (2012) Hypoxic events stimulate nitrogen recycling in a shallow salt wedge estuary: The Yarra River Estuary, Australia. Limnology \& Oceanography, 57, 1427-1442.

Robson, B, P.A. Bukaveckas, and D.P Hamilton (2008) Modelling and mass balance assessments of nutrient retention in a seasonally-flowing estuary (Swan River Estuary, Western Australia). Estuarine and Coastal Shelf Science, 76, $282-292$.

Simon, N.S. (1988) Nitrogen cycling between sediment and the shallow-water column in the transition zone of the Potomac River and Estuary: I. Nitrate and ammonium fluxes. Estuarine and Coastal Shelf Science, 26, 483:497 